\title{
Synthesis and application of magnetite dextran-spermine nanoparticles in breast cancer hyperthermia
}

\author{
Reza Avazzadeh $^{1}$ - Ebrahim Vasheghani-Farahani ${ }^{1} \cdot$ Masoud Soleimani $^{2}$ \\ Saeid Amanpour ${ }^{3} \cdot$ Mohsen Sadeghi $^{1}$
}

Received: 24 March 2017 / Accepted: 7 June 2017/Published online: 17 June 2017

(c) The Author(s) 2017. This article is an open access publication

\begin{abstract}
Cancer treatment has been very challenging in recent decades. One of the most promising cancer treatment methods is hyperthermia, which increases the tumor temperature $\left(41-45^{\circ} \mathrm{C}\right)$. Magnetic nanoparticles have been widely used for selective targeting of cancer cells. In the present study, magnetic dextran-spermine nanoparticles, conjugated with Anti-HER2 antibody to target breast cancer cells were developed. The magnetic dextran-spermine nanoparticles (DMNPs) were prepared by ionic gelation, followed by conjugation of antibody to them using EDCNHS method. Then the Prussian blue method was used to estimate the targeting ability and cellular uptake. Cytotoxicity assay by MTT showed that antibody-conjugated MNPs (ADMNPs) have no toxic effect on SKBR3 and human fibroblast cells. Finally, the hyperthermia was applied to show that synthesized ADMNPs, could increase the cancer cells temperature up to $45^{\circ} \mathrm{C}$ and kill most of them without affecting normal cells. These observations proved that Anti-HER2 conjugated magnetic dextranspermine nanoparticles can target and destroy cancer cells and are potentially suitable for cancer treatment.
\end{abstract}

Keywords Cancer hyperthermia - Anti-HER2 - Magnetic nanoparticles $\cdot$ Dextran-spermine

Ebrahim Vasheghani-Farahani

EVF@modares.ac.ir

1 Biomedical Engineering Group, Faculty of Chemical Engineering, Tarbiat Modares University, Tehran, Iran

2 Hematology Group, Faculty of Medical Sciences, Tarbiat Modares University, Tehran, Iran

3 Cancer Biology Research Center, Tehran University of Medical Sciences, Tehran, Iran

\section{Introduction}

Breast cancer is a malignant tumor that originates from healthy mammary gland cells which is most frequent among women aged between 50 and 70 . It is the most common type of cancer among women which affects one in eight women on average (Alphandery 2014; Matsen and Neumayer 2013; Tinoco et al. 2013). Surgery, chemotherapy and radiotherapy are the most common strategies to treat breast cancer. These conventional cancer therapies, having limitations such as toxic side effects and drug resistance, have often failed to completely eliminate the tumor (Chalkidou et al. 2011; Chen et al. 2014; Debnath et al. 2016; Sahu et al. 2013).

Hyperthermia is the application of heat to destroy the tumor cells or sensitize them to drugs and radiation by increasing blood flow and inducing immune responses. The tumor cells, by having poorly developed vessels and nervous system, so insufficient oxygen supply and inability to dissipate heat, are sensitive to temperatures in the range of $41-45^{\circ} \mathrm{C}$, which damages tumor cells irreversibly, while normal cells can tolerate even higher temperatures (Chen et al. 2009; Kawashita et al. 2005; Lin et al. 2012; Meenach et al. 2010; Purushotham and Ramanujan 2010; Rao et al. 2013; Sen et al. 2011). An adequate amount of heat should be delivered to the tumor so that it reaches the desired temperatures, or it may induce resistance. The magnetic fluid hyperthermia is a non-invasive method which can deliver the desired heat to deep-seated tumors without damaging healthy tissues. It predominantly uses superparamagnetic iron oxide nanoparticles (SPIONs) which are biocompatible, non-toxic and easy to synthesize. They have raised great attention in biomedical applications such as magnetic resonance imaging, drug delivery and magnetic hyperthermia where SPIONs produce heat in an alternating magnetic field 
(AFM) thorough either Néel or Brownian relaxation (Lin et al. 2012; Ma et al. 2004; Sadhukha et al. 2013; Stocke et al. 2016; Yallapu et al. 2011).

The magnetic particles can be introduced into the body via the systemic circulation and guided to the target site under the influence of magnetic field or via direct injection into the tumor. However, in case of intravenous injection, the particle size should be controlled as well as surface modification in a way that inhibits protein adsorption and phagocytosis. SPIONs, having a hydrophobic nature, tend to aggregate, so have a short half-life in blood circulation, leading to poor bioavailability. To resolve this challenge, polymeric and inorganic nanoparticles, liposomes, micelles and phospholipid complexes have been used to encapsulate them for delivery. Among them, polymeric nanoparticles are emerging as one of the best options due to their higher stability (Cole et al. 2011a; Lin et al. 2012; Liu et al. 2011; Rao et al. 2013). The particles can be delivered to the tumor either passively thorough vascularization and the enhanced permeation and retention effect (EPR) or actively thorough receptor-mediated endocytosis. However, active targeting results in higher local concentrations of nanoparticles and lower systemic concentrations, which is essential for more effective treatment (Cole et al. 2011; Kruse et al. 2014; Lin et al. 2012; Ling et al. 2017; Ruoslahti et al. 2010; Wuang et al. 2008).

In this study an atni-HER2 conjugated dextran-spermine magnetic nanoparticle was developed for breast cancer magnetic hyperthermia. Atni-HER2 is a humanized IgG monoclonal antibody directed against the extracellular domain of the human epidermal growth factor receptor 2 (HER-2), which is overexpressed in some types of breast cancer cells. The antibody can be efficient in cell uptake of the carrier system and nanoparticles thorough the internalization ability of AntiHER-2 (Moore and Cobleigh 2007; Wuang et al. 2008). First, dextran-spermine was synthesized and the amine content was evaluated as described in the literature (Azzam et al. 2002). The dextran-spermine magnetic nanoparticles (DMNPs) were prepared using ionic gelation method. The size, zeta potential and morphology of the nanoparticles were analyzed. Finally, the antibody was conjugated to the nanoparticles. The antiHER2 conjugated dextran-spermine magnetic nanoparticles (ADMNPs) were characterized and compared to DMNPs and iron oxide nanoparticles (MNPs) in terms of biocompatibility, cell uptake and in vitro hyperthermia for cancerous SKBR3 and normal fibroblast cells.

\section{Materials and methods}

\section{Dextran-spermine synthesis}

Dextran-spermine conjugate was prepared according to Azzam method (Azzam et al. 2002). Briefly, $10 \mathrm{~g}$ dextran was dissolved in $200 \mathrm{~mL}$ doubly deionized water (DDW); and potassium periodate at molar ratio of $1: 1$ was added to the dextran solution. The resulting solution was stirred for $8 \mathrm{~h}$ in a dark room to form a clear-yellow solution. This solution was dialyzed for 2 days against DDW in a cellulose tube with 12,000 Dalton MW cutoff at $4{ }^{\circ} \mathrm{C}$ while the dialysis water was refreshed every $6 \mathrm{~h}$. Then the purified solution was freeze-dried to obtain a white powder (oxidized dextran). A solution of $0.57 \mathrm{~g}$ of oxidized dextran in $57 \mathrm{~mL}$ of DDW was slowly (during $5 \mathrm{~h}$ ) added to a solution containing 1.25 equimolar amount of the spermine dissolved in $100 \mathrm{~mL}$ of $0.1 \mathrm{M}$ borate buffer. The resulting solution was stirred for $24 \mathrm{~h}$ at room temperature, then dialyzed against DDW in a cellulose tube with 3500 Dalton MW cutoff at $4{ }^{\circ} \mathrm{C}$. The amine-based conjugates were obtained after reducing the imines' conjugates by adding $1 \mathrm{~g} \mathrm{NaBH} 4$ to the mixture at room temperature and stirring for $48 \mathrm{~h}$. The reduction was repeated by adding another $1 \mathrm{~g}$ $\mathrm{NaBH} 4$ and stirring for $24 \mathrm{~h}$. The resulting solution was dialyzed again using a 3500-MW cutoff tubing (Membrane Filtration Products Inc., San Antonio, TX, USA), then freeze-dried to obtain a yellow amine-based conjugate powder. The synthesized polycation was characterized for its primary amine content and structure using TNBS method (Mohammad-Taheri et al. 2012) and H-NMR analysis. Figure1 shows the schematical dextran-spermine synthesis route.

\section{Characterization of the synthesized polymer}

H-NMR analysis and TNBS method were used to determine the formation of the primary amine groups. For TNBS method, dextran-spermine was dissolved in $0.1 \mathrm{M}$ sodium bicarbonate solution $(\mathrm{pH} 8.5)$ to obtain solutions ranging 20-200 $\mu \mathrm{g} / \mathrm{mL}$. A standard calibration curve for $\mathrm{L}-$ lysine was plotted. $1 \%$ TNBS was added to $0.1 \mathrm{M}$ sodium bicarbonate solution and $500 \mu \mathrm{g}$ of the resulting solutions was added to $1 \mathrm{~mL}$ of each sample. The samples were incubated for $2 \mathrm{~h}$ at $37{ }^{\circ} \mathrm{C}$. Finally, $500 \mu \mathrm{g}$ sodium dodecyl sulfate $(10 \% \mathrm{w} / \mathrm{v})$ and $250 \mu \mathrm{L} \mathrm{HCl}(1 \mathrm{~N})$ were added to each sample to stop the reaction. The absorbance of the samples was recorded at $345 \mathrm{~nm}$ using a spectrophotometer (UV-Vis-CARY50). The primary amine content was calculated according to the calibration curve. H-NMR spectra were recorded on a BRUKER DRX500 AVANCE (500 MHz) instrument using DDW as solvent. Values were recorded as ppm relative to internal standard (TMS).

\section{Preparation of SPION-loaded dextran-spermine nanoparticles}

The MNP-loaded dextran-spermine nanoparticles (DMNP) were prepared by ionic gelation technique as shown in 


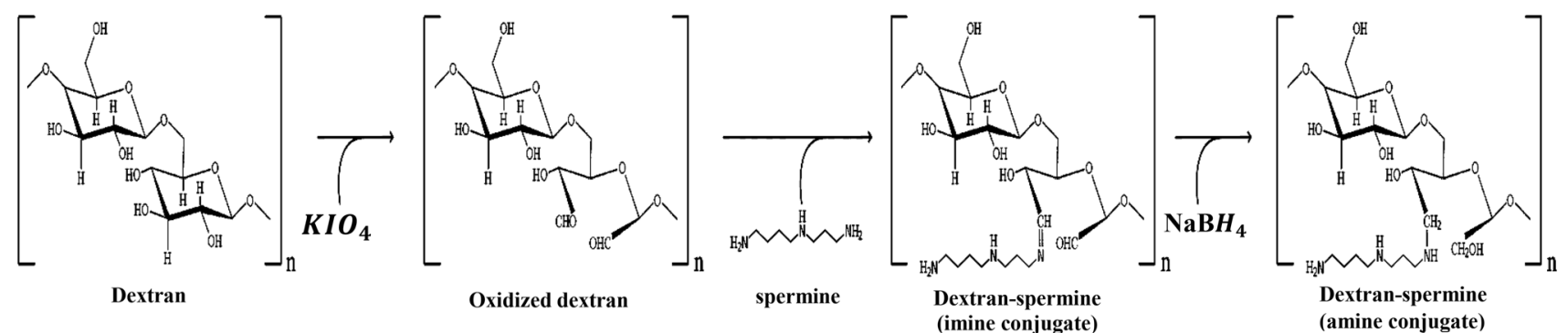

Fig. 1 Dextran-spermine formation

Fig. 2. In brief, $5 \mathrm{mg}$ SPION (MNP) was added to $2 \mathrm{~mL}$ of a $2.92 \mathrm{mg} / \mathrm{mL}$ dextran-spermine solution and sonicated for 5 min. The cationic dextran nanoparticles were formed upon addition of $800 \mu \mathrm{L}$ of an aqueous tripolyphosphate (TPP) solution to the above mentioned suspension under mechanical stirring. Finally, the suspension was centrifuged first at $5000 \mathrm{~g}$ for $3 \mathrm{~min}$ to separate larger particles and then at 30,000 $\mathrm{g}$ for $30 \mathrm{~min}$ to remove free MNPs and isolate the nanoparticles with desired size $(80-100 \mathrm{~nm})$.

\section{Characterization of the MNP-loaded nanoparticles}

DLS analysis was carried out to determine the size distribution and zeta potential of the DMNP using a particle size analyzer (PSA) (Malvern, 3000 HAS, England). The DMNPs were suspended in purified water and sonicated to produce a homogenous suspension for measurement. The zeta potential of the nanoparticles was also measured to confirm their surface charge. TEM imaging (Zeis-EM10C$80 \mathrm{kV}$ ) was also used to evaluate the size, morphology and encapsulation of the nanoparticles. A drop of well-dispersed nanoparticle suspension was placed on a copper grid and then dried at ambient condition before its attachment to the sample holder of the microscope.

\section{Conjugation of the antibody to the MNP-loaded nanoparticles}

The antibody was conjugated to the nanoparticles using EDC-NHS (Fischer 2010) as shown schematically in Fig. 3. In this method, the carboxyl group at the surface of the antibody was activated using EDC-NHS to form an active ester group which would bond to the amine group at the

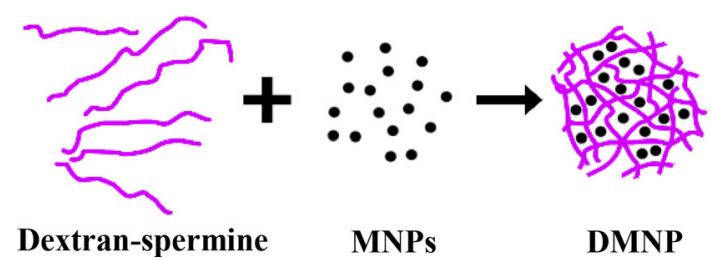

Fig. 2 DMNPs formation surface of the nanoparticles (Hermanson 2013). In brief, the antibody was dissolved in a reaction buffer ( $\mathrm{pH}$ 6) containing MES 0.05 $\mathrm{M}$ and $\mathrm{NaCl} 0.5 \mathrm{M}$. Then EDC (2 mM) and NHS ( $5 \mathrm{mM}$ ) were added to the mixture. After stirring for $15 \mathrm{~min}$ at room temperature, $1 \mu \mathrm{L}$ mercaptoethanol was added to stop the reaction. The MNP-loaded nanoparticles, suspended in a MES buffer at $\mathrm{pH} 7.5$, were added after $10 \mathrm{~min}$ of further stirring. The final suspension was stirred for $2 \mathrm{~h}$ at room temperature. Finally the antibody-conjugated nanoparticles were centrifuged, separated and redispersed in DDW.

\section{Characterization of antibody-conjugated nanoparticles}

Size distribution and zeta potential of antibody-conjugated MNP-loaded dextran-spermine nanoparticles (ADMNP) were also measured using a particle size analyzer. Comparing these results to those of the DMNP can confirm the antibody conjugation. Antibody conjugation to the nanoparticles was also evaluated using Bradford assay. The Bradford solution was prepared by adding $100 \mathrm{mg}$ of Coomassie brilliant blue $\mathrm{G} 250$ to $50 \mathrm{~mL}$ ethanol, then mixing by $100 \mathrm{~mL}$ phosphoric acid $(85 \% \mathrm{w} / \mathrm{w})$ and finally adding them to DDW to reach the volume of $1 \mathrm{~L}$. Then $5 \mathrm{~mL}$ of the solution was added to different concentrations of the antibody ranging from 0 to $1 \mathrm{mg} / \mathrm{mL}$ and their absorbances at $600 \mathrm{~nm}$ were measured. These values were plotted to form a standard curve. The amount of the antibody in the supernatant of the centrifuged antibody-conjugated nanoparticles was determined by comparing to the standard curve.

\section{Cell culture}

Immortalized primary human fibroblast and breast cancer SKBr3 cells obtained from cell bank (Stem cell technology research center, Tehran, Iran) were grown in T75 cell culture flasks in $3 \mathrm{~mL}$ of complete medium. The medium consisted of Dulbecco's Modified Eagles Medium (DMEM), with $10 \%$ of fetal bovine serum (FBS) and Penicillin/Streptomycin. The cells were incubated in an incubator (RS Biotech Galaxy) at $37{ }^{\circ} \mathrm{C}$ with a $5 \% \mathrm{CO} 2$ atmosphere until they reach the suitable confluence. 


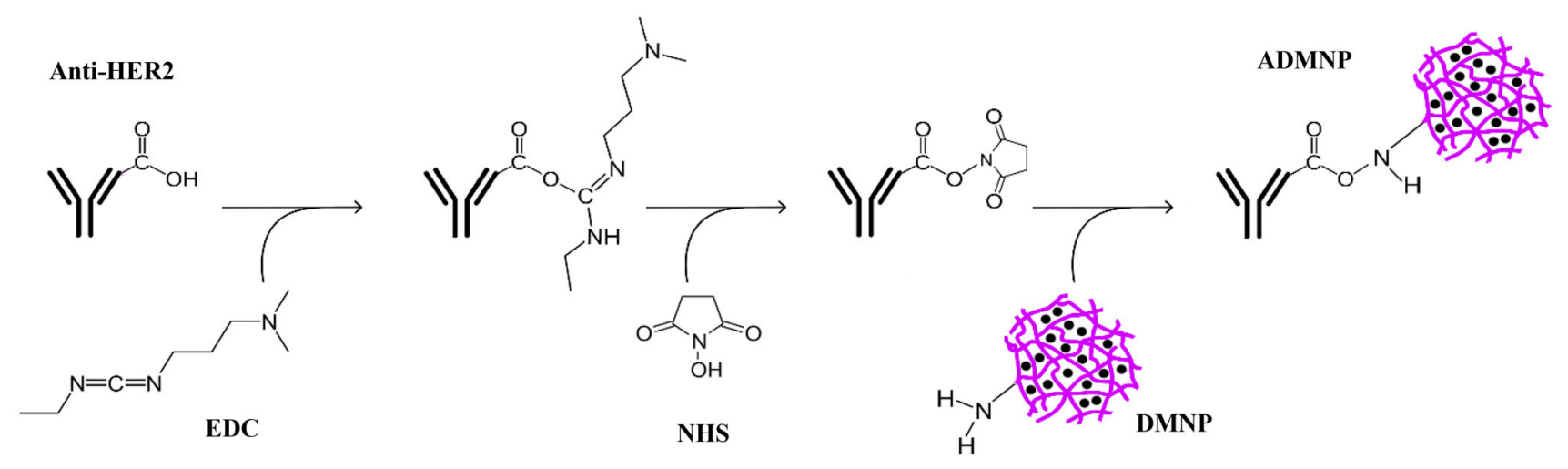

Fig. 3 Conjugation of anti-HER2 to DMNPs using EDC-NHS

\section{Cytotoxicity assay}

In vitro cytotoxicities of MNPs, DMNPs and ADMNPs against breast cancer SKBR3 and normal fibroblast cells were evaluated based on the MTT (3-[4,5-dimethylthiazol2-yl]-2,5-diphenyltetrazolium bromide) assays. SKBR3 and human fibroblast cells with cell density of 5000 per well were dispensed in 96-well plates in triplicate, and 200 $\mu \mathrm{L}$ of fresh medium was added to each well and incubated for $48 \mathrm{~h}$. Then, the cells were treated with different concentrations of the nanoparticles $(50,80$ and $150 \mu \mathrm{g} / \mathrm{mL}$ medium). A control group containing no particle was also considered for each cell type. The samples were incubated for 24 and $48 \mathrm{~h}$. After the incubation, the wells were washed with $200 \mu \mathrm{L}$ PBS and overlaid with $50 \mu \mathrm{L}$ fresh media containing $0.5 \mathrm{mg} / \mathrm{mL}$ of MTT reagent and incubated for $4 \mathrm{~h}$. Subsequently, the media were aspirated and formazan crystals were solubilized in $200 \mu \mathrm{L}$ dimethyl sulfoxide (DMSO). The averaged absorbance at $570 \mathrm{~nm}$ for each treatment group was normalized to the zero-time viability values.

\section{Uptake assay}

Cellular uptake was evaluated using iron staining method. For this purpose, the cultured SKBR3 and fibroblast cells were seeded in 96-well plates with cell density of 5000 per well and $200 \mu \mathrm{L}$ of fresh media was added. The cells were left to incubate for $24 \mathrm{~h}$, prior to addition of nanoparticles. Three sample groups (MNP, DMNP and ADMNP) and a control were considered for each cell type. The samples were overlaid by $200 \mu \mathrm{L}$ of fresh media containing $80 \mu \mathrm{g} /$ $\mathrm{mL}$ nanoparticles and after $6 \mathrm{~h}$ of incubation, the culture medium was removed and the cells were fixed upon addition of $500 \mu \mathrm{L} 10 \%$ neutral buffered formalin. After $20 \mathrm{~min}$, the formalin was replaced by $500 \mu \mathrm{L}$ Prussian blue solution, containing $5 \% \mathrm{w} / \mathrm{v}$ potassium ferrocyanide and $5 \% \mathrm{v} / \mathrm{v} \mathrm{HCl}$ and left till blue stains appeared. Prussian blue

is a prototype of mixed-valence transition-metal hexacyanoferrates with the general formula of $\mathrm{Fe}_{4}\left[\mathrm{Fe}(\mathrm{CN})_{6}\right]_{3}$ (Cheng et al. 2014). The cells then were washed twice by PBS and examined by microscope.

\section{Hyperthermia study}

For in vitro hyperthermia study, SKBR3 and fibroblast cells were seeded in the 96-well plates with the concentration of 5000 cells per well and $200 \mu \mathrm{L}$ of fresh media was added. After $48 \mathrm{~h}$ of incubation, the media was replaced by $200 \mu \mathrm{L}$ of fresh media containing optimum concentration of $80 \mu \mathrm{g} / \mathrm{mL}$ (Attar et al. 2016) of three magnetic nanoparticle groups (MNP, DMNP and ADMNP). A control group with no magnetic substance was also considered for each cell type. After $8 \mathrm{~h}$ of incubation, the wells were washed with $200 \mu \mathrm{L}$ PBS and overlaid with $200 \mu \mathrm{L}$ fresh media. The cells were left to incubate overnight prior to initiating the test. The samples were placed in the copper coil of a radio frequency generator at $80 \mathrm{kHz}$ frequency with $150 \mathrm{kA} / \mathrm{m}$ field. The temperature was monitored over the test.

\section{Statistical analysis}

All experiments were performed at least in triplicate. Microsoft office excel was used for $t$ tests (paired $t$ test with unequal variances) to determine any significance in the observed data. The $P$ value $<0.05$ was considered statistically significant.

\section{Results and discussion}

\section{Characterization of the synthesized polymer}

The primary amine content of the synthesized dextranspermine conjugate was determined according to an L- 
lysine standard curve. For the dextran-spermine solution an absorbance of 0.577 was read; according to the curve, this absorbance is equivalent to the concentration of $19.75 \mu \mathrm{g} /$ $\mathrm{mL}$ of L-lysine. So considering that L-lysine has 2 amine groups, the primary amine group content for synthesized dextran-spermine was $1.43 \mathrm{mM} / \mathrm{g}$ that is within the range of previous studies (Mohammad-Taheri et al. 2012; Tarvirdipour et al. 2016). The structure of the synthesized polymer was evaluated using H-NMR analysis (Fig. 4). The H-NMR spectra were as follows:

$1.4405\left(\mathrm{~m}, 4 \mathrm{H}\right.$, dextran- $\mathrm{CH}_{2} \mathrm{NH}\left(\mathrm{CH}_{2}\right)_{3} \mathrm{NH} \mathrm{CH} \mathrm{CH}_{2} \mathrm{CH}_{2}$ $\left.\mathrm{CH}_{2} \mathrm{CH}_{2} \mathrm{NH}\left(\mathrm{CH}_{2}\right)_{3} \mathrm{NH}_{2}\right), 1.6106$ (m, 4H, dextran- $\mathrm{CH}_{2}$ $\left.\begin{array}{llllll}\mathrm{NH} & \mathrm{CH}_{2} \mathrm{CH}_{2} \mathrm{CH}_{2} & \mathrm{NH} & \left(\mathrm{CH}_{2}\right)_{4} \mathrm{NH} & \mathrm{CH}_{2} \mathrm{CH}_{2} \mathrm{CH}_{2} & \mathrm{NH}_{2}\end{array}\right)$, 2.6303 (m, 14H, dextran- $\mathrm{CH}_{2} \mathrm{NH} \mathrm{CH} \mathrm{CH}_{2} \mathrm{CH}_{2} \mathrm{NH} \mathrm{CH}$ $\mathrm{CH}_{2} \mathrm{CH}_{2} \mathrm{CH}_{2} \mathrm{NH} \mathrm{CH} \mathrm{CH}_{2} \mathrm{CH}_{2} \mathrm{NH}_{2}$ ), 3.4150-3.5860 (m, glycoside hydrogens) and $4.6822(\mathrm{~m}, 1 \mathrm{H}$, anomeric hydrogen).

\section{Characterization of the MNP-loaded nanoparticles}

Superparamagnetic materials have the ability to become magnetized upon exposure to a magnetic field without showing permanent magnetization once removed from the field. This ability is used in nanomedicine as an efficient tool to move nanoparticles into the body towards target sites (Tampieri et al. 2012). TEM imaging and DLS analysis were used to evaluate the average size, size distribution, morphology and encapsulation of the nanoparticles. The zeta potential of the nanoparticles was also measured. As shown in Table 1, the mean size of the nanoparticles was $67.3 \mathrm{~nm}$ with zeta potential of $+30 \mathrm{mV}$. In cancer therapeutics, nanoparticles smaller than $200 \mathrm{~nm}$ are desirable (Yallapu et al. 2011) and nanoparticles with the hydrodynamic diameter of $10-100 \mathrm{~nm}$ are considered optimal for biomedical applications (Cole et al. 2011). The TEM images in Fig. 5 show DMNPs with $60-80 \mathrm{~nm}$ size and good encapsulation of MNPs in dextran-spermine network.

\section{Characterization of the antibody-conjugated nanoparticles}

DLS analysis was carried out to confirm the conjugation of the antibody to DMNPs. As reported in Table 1, the mean size of ADMNPs and the antibody was 85.6 and $7.5 \mathrm{~nm}$, respectively, with corresponding zeta potentials of +3.47 and $-12.5 \mathrm{mV}$. These particles are still within optimal size range and with a cationic surface charge, can be easily uptaken by cancer cells. These results indicate that the average size of DMNPs increased upon antibody

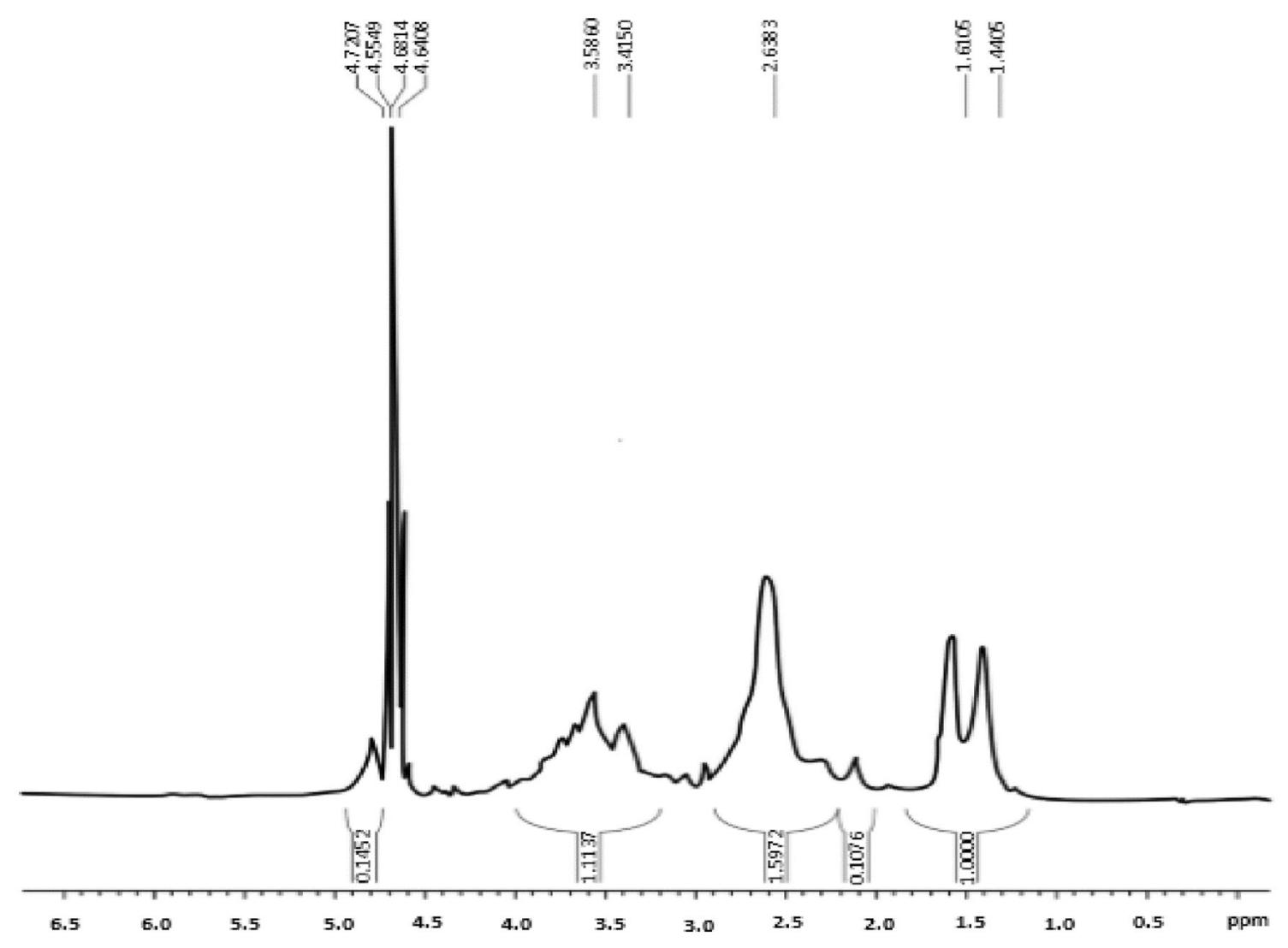

Fig. 4 H-NMR spectra of synthesized dextran-spermine 
Table 1 Comparison of average size and zeta potential of the DMNPs, the antibody and the ADMNPs

\begin{tabular}{lrr}
\hline Sample & Average size (nm) & Zeta potential (mV) \\
\hline Dextran-spermine encapsulated Iron oxide nanoparticles (DMNPs) & 67.3 & +30 \\
Anti-HER2 antibody & 7.5 & -12.5 \\
Anti-HER2 conjugated dextran-spermine encapsulated iron oxide nanoparticles (ADMNPs) & 85.6 & +3.47 \\
\hline
\end{tabular}

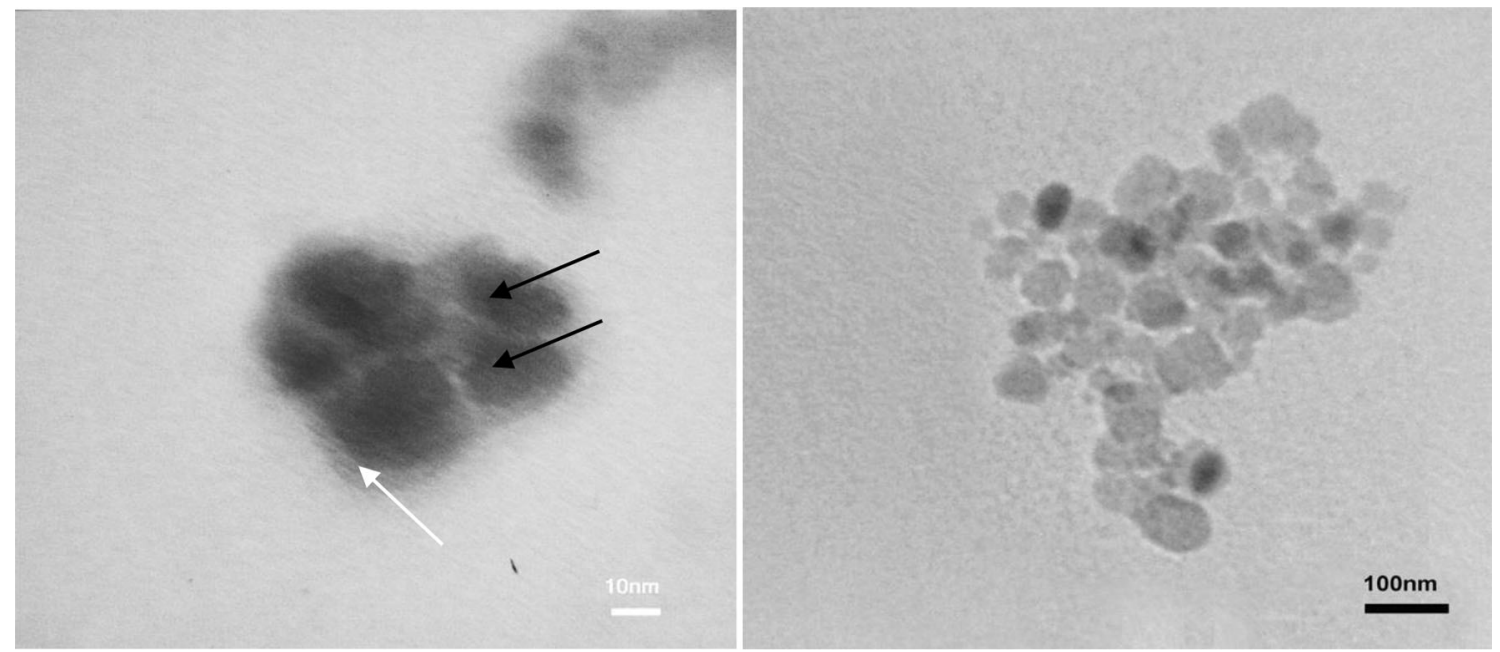

Fig. 5 TEM images of the DMNPs: black arrows show the MNPs encapsulated in dextran-spermine polymer, and the white arrow shows the polymer

conjugation; but the extent of their positive charge decreased due to the negative charge of the antibody. These observations confirm the successful conjugation of the antibody to the DMNPs.

Bradford assay was also used to quantitatively evaluate the antibody conjugation. A standard absorbance curve was plotted for the antibody concentration. The supernatant of the centrifuged antibody-conjugated nanoparticles suspension was analyzed using Elisa reader and conjugation of $24.1 \mu \mathrm{g}$ antibody to $1 \mathrm{mg}$ of the nanoparticles was obtained. Higher antibody conjugation that resulted in negatively charged nanoparticles have been reported; but these negatively charged nanoparticles did not show good cell uptake characteristics (Nahta and Esteva 2006; Purushotham and Ramanujan 2010; Rao et al. 2013).

\section{Cytotoxicity assay}

Prior to application of any biomaterial in therapy, its potential toxic effects to cells should be evaluated (Dennis et al. 2009). The standard MTT assay was used to determine the cytotoxic effects of MNP, DMNP and ADMNP on SKBR3 and fibroblast cells. The cells were treated by various concentrations $(50,80$ and $150 \mu \mathrm{g} / \mathrm{mL})$ of different nanoparticles and their viabilities after 24 and $48 \mathrm{~h}$ were compared to zero-time viability (Fig. 6). For each cell type, a control group without nanoparticle was considered as a reference and the viability values were normalized to the control value. The results confirmed that nanoparticle groups were not cytotoxic to fibroblast cells except for the MNP group which decreased the cell viability slightly after 24 and $48 \mathrm{~h}$ of incubation. The MNP cytotoxicity increased at higher concentrations, but still at worst case, with the highest concentration $(150 \mu \mathrm{g} /$ $\mathrm{mL}$ ) and after $48 \mathrm{~h}$, less than $9 \%$ cytotoxicity was observed, so MNPs can be considered nontoxic to fibroblast cells at these concentrations. Previous studies indicated that coated MNPs were not toxic at low concentrations (Easo and Mohanan 2013; Sadhasivam et al. 2015). Encapsulating the MNPs in the dextran-spermine polymer allow them to be used at higher concentrations. The same can be said for SKBR3 cells; the cytotoxic effect of MNPs on the SKBR3 cells was negligible and less than $10 \%$. However, the DMNP group had absolutely no toxic effect on the cancer cells, as the cell viability after $48 \mathrm{~h}$ was at the same level as the control group. Since dextran is a hydrophilic, water-soluble polymer that is inert in biological systems (İmren et al. 2006), dextranencapsulated MNPs were not toxic. Coated MNPs have been reported to be non-toxic to SKBR3 cells (Easo and Mohanan 2013; Sadhasivam et al. 2015). The ADMNPs induced a $13 \%$ decrease of the viability after $48 \mathrm{~h}$ that is 

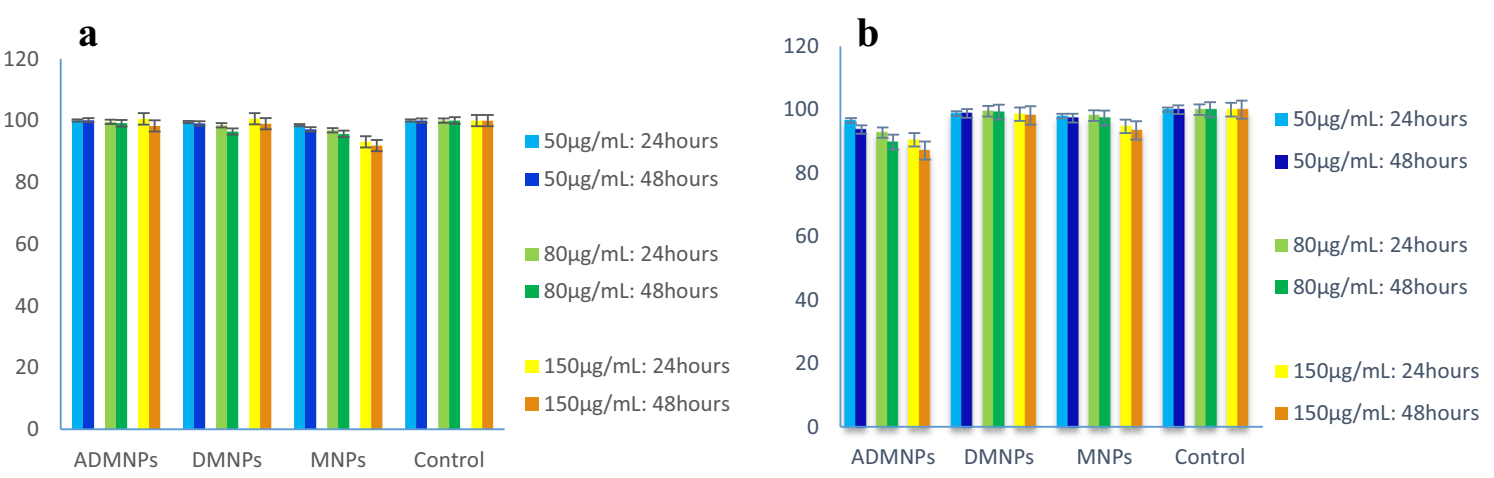

Fig. 6 Cytotoxicities of various concentrations and incubation times of ADMNPs, DMNPs and MNPs measured by viabilities of a fibroblast cells and b SKBR3 calls relative to non-toxic control

due to anti-proliferative effect of herceptin to HER-2 expressing cells (Chen et al. 2009; Nahta and Esteva 2006).

\section{Uptake assay}

Targeting ability is a must when it comes to cancer treatment, since cancer therapeutics are toxic not only to cancer cells, but also to normal healthy tissues. As for hyperthermia, heating healthy tissues might be harmful; thus, the nanoparticles should be delivered exactly to the tumor site and nowhere else. Iron staining method was used to evaluate the targeting ability of the ADMNP, DMNP and MNPs. The SKBR3 and fibroblast cells were treated by $80 \mu \mathrm{g} / \mathrm{mL}$ magnetic nanoparticles; the cells were washed after $6 \mathrm{~h}$ of incubation and the iron particles were stained using Prussian blue. The microscopic images of the cells in Fig. 7 show that ADMNPs have entered the cancer cells with a great number and covered the cells completely, but no blue stain was observed in fibroblast cells. The results for DMNPs showed no difference between cancer and normal cells. These particles having positive surface charge are capable of entering cells, but as they do not have any specific receptor, do it with no preference and would not be a good choice when it comes to hyperthermia treatment. Finally, the MNPs showed less cellular uptake by the cells. These particles with low uptake and no targeting ability cannot be considered as a suitable candidate for hyperthermia. The ADMNPs with good targeting ability and cellular uptake can be considered to be the most promising carrier for cancer hyperthermia.

\section{Hyperthermia study}

In vitro hyperthermia studies were done under $\mathrm{AC}$ magnetic field on SKBR3 and fibroblast cells. The cells were seeded in a 96-well plate and each was treated by $80 \mu \mathrm{g} / \mathrm{ml}$ of 3 nanoparticle groups (MNP, DMNP and ADMNP); a control group was also considered. These samples were subjected to the magnetic field for $20 \mathrm{~min}$. In the presence of an alternating magnetic field (AFM), iron oxide magnetic nanoparticles generate heat and can induce hyperthermia (Dennis et al. 2009; Kossatz et al. 2015). The temperature elevation for each group is shown in Fig. 8a. After the hyperthermia test, the cells were incubated for $24 \mathrm{~h}$ prior to undergoing MTT assay to evaluate cell viability. The cell viability of the groups after the hyperthermia test is shown in Fig. 8b.

As shown in Fig. 8a, the control groups for SKBR3 and fibroblast cells, having no magnetic content, did not show any change in temperature. The Fibroblast samples did not experience any significant raise of temperature except for the DMNP sample, which came close to the hyperthermia region. The reason is that these cationic nanoparticles with size $<100 \mathrm{~nm}$ are capable of entering the cells and as they do not have any specific targeting ability (antibody), they enter any cell type indiscriminately (Cole et al. 2011).The MNPs and DMNPs, due to significant uptake into the SKBR3 cells, were able to heat them to 40 and $41{ }^{\circ} \mathrm{C}$, respectively. The most temperature elevation was observed in SKBR3 cells containing ADMNPs. This group is the only one that reached the hyperthermia temperatures, so the most toxicity was expected for this group.

Figure $8 \mathrm{~b}$ shows that the cytotoxicity in all fibroblast groups was negligible, so none of the groups were able to generate sufficient amount of heat to damage the cells. However, the ADMNPs, having targeting ability, did not enter the fibroblast cells and the cellular uptake of the MNPs and DMNPs was not enough to induce hyperthermia effect. Figure 8a shows that fibroblast groups did not reach the hyperthermia temperatures and no significant cytotoxicity was expected. The only group which was able to kill some of the fibroblast cells was the DMNPs group. Although the uptakes of MNP and 

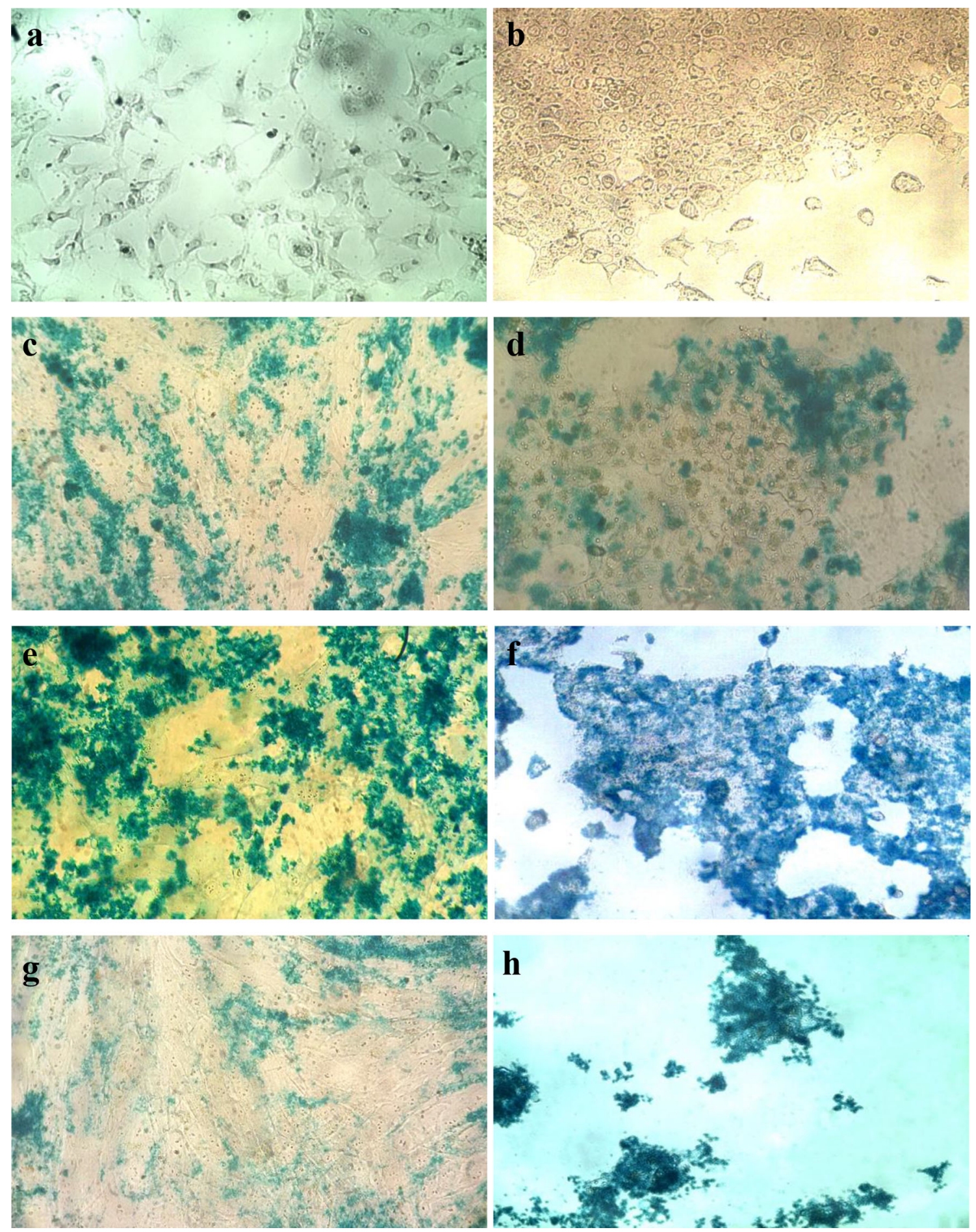

Fig. 7 Iron staining results a human fibroblast cells (blank), b SKBR3 cells (blank), c human fibroblast cells stained by MNPs, d SKBR3 cells stained by MNPs, e human fibroblast cells stained by

DMNPs, $\mathbf{f}$ SKBR3 cells stained by DMNPs, $\mathbf{g}$ human fibroblast cells stained by ADMNPs and $\mathbf{h}$ SKBR3 cells stained by ADMNPs

DMNP groups were not significantly different for SKBR3 and fibroblast cells, cytotoxicity was higher for cancer cells due to more sensitivity of the cancer cells to high temperatures (Javidi et al. 2015). Finally, the

ADMNPs group with excellent targeting ability and good temperature elevation under AFM was able to kill over 65 percent of cancerous cells without affecting normal fibroblast cells. 


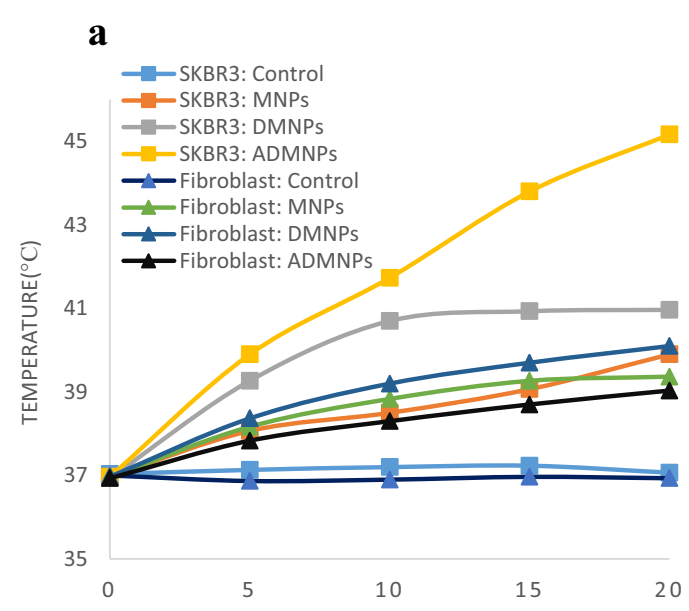

Fig. 8 Hyperthermia study of SKBR3 and fibroblast cells: a temperature elevations of SKBR3 and fibroblast cells by heating effects of ADMNPs, DMNPs and MNPs under AFM, and $\mathbf{b}$ viabilities of

\section{Conclusion}

Dextran-spermine polymer with $1.43 \mathrm{mM}$ amine groups was successfully synthesized. Magnetic nanoparticles of dextran-spermine (DMNPs) with a size of $67.3 \mathrm{~nm}$ and zeta potential of and $+30 \mathrm{mV}$ were prepared. These characteristics make the particles ideal for biomedical applications. EDC-NHS method was used to conjugate anti-HER2 antibody to DMNPs that resulted in nanoparticles with a size and surface charge of $85.6 \mathrm{~nm}$ and $+3.47 \mathrm{mV}$, respectively. These antibody-conjugated magnetic nanoparticles (ADMNPs) were compared to DMNPs and MNPs in terms of cytotoxicity, targeting ability and hyperthermia efficiency. The results showed that ADMNPs were not toxic to normal cells, while they showed a slight toxicity to SKBR3 cells. However, they can target HER2-expressing cancer cells and enter them effectively. In vitro hyperthermia confirmed the ability of ADMNPs in targeting cancer cells and heating them up to hyperthermia range while more than $63 \%$ of cancer cells were destroyed over a 20-min treatment course. Based on the in vitro results, ADMNPs have a great potential for breast cancer treatment by hyperthermia.

\section{Compliance with ethical standards}

Conflict of interest Authors declare that they have no conflict of interest.

Ethical approval This article does not contain any studies with human participants or animals performed by any of the authors.

Open Access This article is distributed under the terms of the Creative Commons Attribution 4.0 International License (http://crea tivecommons.org/licenses/by/4.0/), which permits unrestricted use, distribution, and reproduction in any medium, provided you give appropriate credit to the original author(s) and the source, provide a

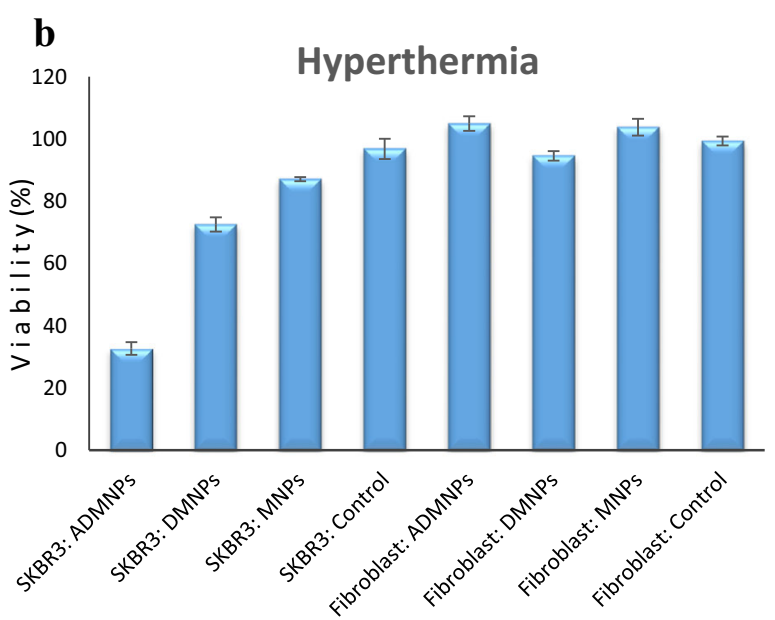

SKBR3 and fibroblast cells containing ADMNPs, DMNPs and MNPs after a 20-min hyperthermia course relative to untreated control group

link to the Creative Commons license, and indicate if changes were made.

\section{References}

Alphandery E (2014) Perspectives of breast cancer thermotherapies. J Cancer 5:472-479. doi:10.7150/jca.8693

Attar MM et al (2016) Thermal analysis of magnetic nanoparticle in alternating magnetic field on human HCT-116 colon cancer cell line. Int J Hyperth 32:858-867

Azzam T, Eliyahu H, Shapira L, Linial M, Barenholz Y, Domb AJ (2002) Polysaccharide-oligoamine based conjugates for gene delivery. J Med Chem 45:1817-1824

Chalkidou A et al (2011) In vitro application of $\mathrm{Fe} / \mathrm{MgO}$ nanoparticles as magnetically mediated hyperthermia agents for cancer treatment. J Magn Magn Mater 323:775-780. doi:10.1016/j. jmmm.2010.10.043

Chen TJ, Cheng TH, Chen CY, Hsu SC, Cheng TL, Liu GC, Wang YM (2009) Targeted Herceptin-dextran iron oxide nanoparticles for noninvasive imaging of HER2/neu receptors using MRI. J Biol Inorg Chem 14:253-260. doi:10.1007/s00775-008-0445-9

Chen Q, Wang C, Cheng L, He W, Cheng Z, Liu Z (2014) Protein modified upconversion nanoparticles for imaging-guided combined photothermal and photodynamic therapy. Biomaterials 35:2915-2923. doi:10.1016/j.biomaterials.2013.12.046

Cheng L, Gong H, Zhu W, Liu J, Wang X, Liu G, Liu Z (2014) PEGylated Prussian blue nanocubes as a theranostic agent for simultaneous cancer imaging and photothermal therapy. Biomaterials 35:9844-9852. doi:10.1016/j.biomaterials.2014.09.004

Cole AJ, David AE, Wang J, Galban CJ, Yang VC (2011a) Magnetic brain tumor targeting and biodistribution of long-circulating PEG-modified, cross-linked starch-coated iron oxide nanoparticles. Biomaterials 32:6291-6301. doi:10.1016/j.biomaterials.2011.05.024

Cole AJ, Yang VC, David AE (2011b) Cancer theranostics: the rise of targeted magnetic nanoparticles. Trends Biotechnol 29:323-332. doi:10.1016/j.tibtech.2011.03.001

Debnath OB, Saito K, Ito K, Uesaka M (2016) Breast cancer treatment by combining microwave hyperthermia and radiation brachytherapy. In: Antennas and propagation (ISAP), 2016 International Symposium. IEEE, pp 472-473 
Dennis CL et al (2009) Nearly complete regression of tumors via collective behavior of magnetic nanoparticles in hyperthermia. Nanotechnology 20:395103. doi:10.1088/0957-4484/20/39/395103

Easo SL, Mohanan PV (2013) Dextran stabilized iron oxide nanoparticles: synthesis, characterization and in vitro studies. Carbohydr Polym 92:726-732. doi:10.1016/j.carbpol.2012.09. 098

Fischer MJ (2010) Amine coupling through EDC/NHS: a practical approach. Methods Mol Biol (Clifton, NJ) 627:55-73. doi:10. 1007/978-1-60761-670-2_3

Hermanson GT (2013) Chapter 4-zero-length crosslinkers. In: Hermanson GT (ed) Bioconjugate techniques (Third edition). Academic Press, Boston, pp 259-273. doi:10.1016/B978-0-12382239-0.00004-2

İmren D, Gümüşderelioğlu M, Güner A (2006) Synthesis and characterization of dextran hydrogels prepared with chlor- and nitrogen-containing crosslinkers. J Appl Polym Sci 102:4213-4221. doi:10.1002/app.24670

Javidi M, Heydari M, Attar MM, Haghpanahi M, Karimi A, Navidbakhsh M, Amanpour S (2015) Cylindrical agar gel with fluid flow subjected to an alternating magnetic field during hyperthermia. Int J Hyperth 31:33-39. doi:10.3109/02656736. 2014.988661

Kawashita M, Tanaka M, Kokubo T, Inoue Y, Yao T, Hamada S, Shinjo T (2005) Preparation of ferrimagnetic magnetite microspheres for in situ hyperthermic treatment of cancer. Biomaterials 26:2231-2238. doi:10.1016/j.biomaterials.2004.07.014

Kossatz S et al (2015) Efficient treatment of breast cancer xenografts with multifunctionalized iron oxide nanoparticles combining magnetic hyperthermia and anti-cancer drug delivery. Breast Cancer Res 17:66

Kruse AM, Meenach SA, Anderson KW, Hilt JZ (2014) Synthesis and characterization of CREKA-conjugated iron oxide nanoparticles for hyperthermia applications. Acta Biomater 10:2622-2629. doi:10.1016/j.actbio.2014.01.025

Lin TC, Lin FH, Lin JC (2012) In vitro feasibility study of the use of a magnetic electrospun chitosan nanofiber composite for hyperthermia treatment of tumor cells. Acta Biomater 8:2704-2711. doi:10.1016/j.actbio.2012.03.045

Ling Y et al (2017) Highly efficient magnetic hyperthermia ablation of tumors using injectable polymethylmethacrylate- $-\mathrm{Fe}_{3} \mathrm{O}_{4}$. RSC Adv 7:2913-2918

Liu G, Hong RY, Guo L, Liu GH, Feng B, Li YG (2011) Exothermic effect of dextran-coated $\mathrm{Fe}_{3} \mathrm{O}_{4}$ magnetic fluid and its compatibility with blood. Colloids Surf A 380:327-333. doi:10.1016/j. colsurfa.2011.03.006

Ma M, Wu Y, Zhou J, Sun Y, Zhang Y, Gu N (2004) Size dependence of specific power absorption of $\mathrm{Fe}_{3} \mathrm{O}_{4}$ particles in $\mathrm{AC}$ magnetic field. J Magn Magn Mater 268:33-39. doi:10.1016/s03048853(03)00426-8

Matsen CB, Neumayer LA (2013) Breast cancer: a review for the general surgeon. JAMA Surg 148:971-980. doi:10.1001/jama surg. 2013.3393

Meenach SA, Hilt JZ, Anderson KW (2010) Poly(ethylene glycol)based magnetic hydrogel nanocomposites for hyperthermia cancer therapy. Acta Biomater 6:1039-1046. doi:10.1016/j. actbio.2009.10.017

Mohammad-Taheri M, Vasheghani-Farahani E, Hosseinkhani $\mathrm{H}$, Shojaosadati SA, Soleimani M (2012) Fabrication and characterization of a new MRI contrast agent based on a magnetic dextran-spermine nanoparticle system. Iran Polym J 21:239-251. doi:10.1007/s13726-012-0027-0

Moore S, Cobleigh MA (2007) Targeting metastatic and advanced breast cancer. Semin Oncol Nurs 23:37-45. doi:10.1016/j.soncn. 2006.11.007

Nahta R, Esteva FJ (2006) Herceptin: mechanisms of action and resistance. Cancer Lett 232:123-138. doi:10.1016/j.canlet.2005. 01.041

Purushotham S, Ramanujan RV (2010) Thermoresponsive magnetic composite nanomaterials for multimodal cancer therapy. Acta Biomater 6:502-510. doi:10.1016/j.actbio.2009.07.004

Rao W et al (2013) Thermally responsive nanoparticle-encapsulated curcumin and its combination with mild hyperthermia for enhanced cancer cell destruction. Acta Biomater. doi:10.1016/j. actbio.2013.10.020

Ruoslahti E, Bhatia SN, Sailor MJ (2010) Targeting of drugs and nanoparticles to tumors. J Cell Biol 188:759-768. doi:10.1083/ jcb.200910104

Sadhasivam S, Savitha S, Wu CJ, Lin FH, Stobinski L (2015) Carbon encapsulated iron oxide nanoparticles surface engineered with polyethylene glycol-folic acid to induce selective hyperthermia in folate over expressed cancer cells. Int J Pharm 480:8-14. doi:10.1016/j.ijpharm.2015.01.029

Sadhukha T, Wiedmann TS, Panyam J (2013) Inhalable magnetic nanoparticles for targeted hyperthermia in lung cancer therapy. Biomaterials 34:5163-5171. doi:10.1016/j.biomaterials.2013.03. 061

Sahu A, Choi WI, Lee JH, Tae G (2013) Graphene oxide mediated delivery of methylene blue for combined photodynamic and photothermal therapy. Biomaterials 34:6239-6248. doi:10.1016/ j.biomaterials.2013.04.066

Sen A et al (2011) Mild elevation of body temperature reduces tumor interstitial fluid pressure and hypoxia and enhances efficacy of radiotherapy in murine tumor models. Cancer Res 71:3872-3880. doi:10.1158/0008-5472.can-10-4482

Stocke NA, Sethi P, Jyoti A, Chan R, Arnold SM, Hilt JZ, Upreti M (2017) Toxicity evaluation of magnetic hyperthermia induced by remote actuation of magnetic nanoparticles in 3D micrometastasic tumor tissue analogs for triple negative breast cancer. Biomaterials 120:115-125

Tampieri A et al (2012) Intrinsic magnetism and hyperthermia in bioactive Fe-doped hydroxyapatite. Acta Biomater 8:843-851. doi:10.1016/j.actbio.2011.09.032

Tarvirdipour S, Vasheghani-Farahani E, Soleimani M, Bardania H (2016) Functionalized magnetic dextran-spermine nanocarriers for targeted delivery of doxorubicin to breast cancer cells. Int $\mathrm{J}$ Pharm 501:331-341

Tinoco G, Warsch S, Glück S, Avancha K, Montero AJ (2013) Treating breast cancer in the 21st century: emerging biological therapies. J Cancer 4:117-132. doi:10.7150/jca.4925

Wuang SC, Neoh KG, Kang ET, Pack DW, Leckband DE (2008) HER-2-mediated endocytosis of magnetic nanospheres and the implications in cell targeting and particle magnetization. Biomaterials 29:2270-2279. doi:10.1016/j.biomaterials.2008. 01.028

Yallapu MM, Othman SF, Curtis ET, Gupta BK, Jaggi M, Chauhan SC (2011) Multi-functional magnetic nanoparticles for magnetic resonance imaging and cancer therapy. Biomaterials 32:1890-1905. doi:10.1016/j.biomaterials.2010.11.028 